\title{
Nõiaprotsesse Pärnu Maakohtu Arhiivist kuni 1642
}

\author{
Villem Uuspuu
}

Rikkalikku materjali eestlaste usulise arusaamise ja arenemise kohta pakuvad säilinud nõiaprotsesside protokollid. Ühtlasi kerkib neis esile tükike kodumaa ajalugu ja mõndagi 17. sajandi vaimuelule isel oomulikku. Senini on käsitlust leidnud peamiselt omaaegsel E estimaal aset leidnud nõi aprotsessid. Käesolev kirjutis pakub allikalist materjali peamiselt Liivimaal aset leidnud nõiaprotsesside kohta. Esitan protsessest kokkuvõtteid, püüdes esile tõsta iseIoomulikku ja omapärast. Huvitavam ja rikkalikum arhiiv on nende küsimusteval gustamisel Pärnu Maakohtu Arhiiv (=PrnMKA).

I

1633. a. 14. veebruaril on Pärnu Maakohtu istung Pärnus. Kohtu koossei su kuuluvad maakohtunik Friedrich König, Magnus Wolfeldt, Meinert Dittmer, Peter Grohtt, Helmich Grieff ja J ürgen Bremen. Kaebajad on KalleMatz ja Kusala Mathis, kaebealuneTönies'enaine Gret.

Kalle Matz süüdistab kaebeal ust, et viimane nõi dunud tema õllega haigeks. Ta teinud sulasele pulmad, milleks olnud ka saunas kaks tünni õlut. Keegi õlle tooja leidnud kaebeal use õlle juurest. Kui kaebaja esimesena toodud õlut joonud, öelnud Gret, et sinul pole enam eluajal maad vaja. Kolmandal päeval haigestunud kaebaja, käed ja jalad jäänud haigeks, sees ol nud hal b tunneja poleka magada saanud.

Kusala Mathis süüdistab kaebealust lapse surnuksnõidumises. Kaebealune andnud tema kolmeaastasele pojale tüki leiba, mille laps ära söönud. Samal ööl paistetanud laps ja surnud 14 päeva enne jaanipäeva. Kaebaja naine ähvardanud nõida, öeldes, et nõid on tema lapse haigeks nõidunud. Kaebealune proovinud sellepeale last tervendada, pole aga suutnud.

Kaebealune eitab nõi dust. Proovinud küll last tervendada, polevat suutnud aga head ega hal ba teha. Kohus palub kaebajatel 
oma tõendusi kinnitada. Selleks kaebajad annavad üles rea tunnistajaid, kelle kohaletoimetamiseni kaebealune paigutatakse vanglasse. Samal päeval antakse kaebealuselevanglas rohtu, kuna tal kaelast välja roninud maosarnane uss (ein Wurmb einer Schlangen gl eich). Kuuendal märtsil toi mub tunnistajate ülekuulamine.

Wilhel $m$ Szörtz ütleb, et kaebealune tervendas tema naise. Ka öelnud ta, et Kalle Matz künnab nüüd kahe paari härgadega, tuleval aastal ei pea ta enam kündma. Hiljem ol evat ta Matzile pulmas olles nõidunud maod sisse. Ta puhunud õllekibule ja andnud siis sellest Matzile juua. Keegi tunnistaja ütleb, et kaebealune suurustanud, kui ta kohtusse satub, ei sünni talle seni midagi, kuni ta silmad on avatud. Teine tunnistaja ütleb, et Gret läinud jaaniööl välja. J ärgmisel hommikul peale seda leidnud tunnistaja oma piimapüttidest lehma sabakarvu. Kaebeal une ütleb, et ta istunud öösel kivil ja nutnud. Kolmas tunnistaja ütleb, et kaebeal une lubanud kedagi tervendada. Viimaks tunnistab Gret, et või b head teha "Maria-palveja õnnistusega". Ta või b aidata rasedaid ja lapsi.

Enne piinamist (auf dieTortur kommen) tunnistab kaebealune veel, et Szörtz käskinud Kalle Matzi õl lega nõiduda, öeldes, et "õigus" talle ikka midagi ei tee. Ta teinud Szörtzi õpetuse järele vihast Matzi naise vastu.

Nüüd pannakse kohtus Szörtz ja kaebealune "silm silma vastu". Szörtz küsib kaebealuselt, kas sa ei nõidunud surnuks kaks tüdrukut ja ühe mehe? Ka kaebeal une süüdistab Szörtzi nõidumises.

Kaebealust piinatakse (ein mahl angezogen). Nüüd tunnistab ta, et Kanti Hansu naine ja mees jooksevad libahunti (für einen Wolf) ja Simon'i nainejookseb karu (einen bähren). Kui temalt küsitakse, kust ta seda teab, vaikib ta.

7. märtsil kuulatakse Szörtz veel kord üle (exami niret) ja küsitakse, kas ta jääb oma tunnistuse juurde. Siis seatakse ta kaebeal usega veel vastamisi, millest tekib jälle vastastikunesüüdistamine. Szörtz ütleb, et kaebeal une viha pärast temale tunnistab.

Otsus: Kuna kaebealune Gret tunnistab, et nõidus õllega Matzile sisse poggen ja temale schlangen in den Leib gezaubert, ja seda vihast teinud, siis mõistetakse ta el usalt põl etamisele (mit fewer vom leben zum todegerichtet). Kolmandal päeval järgnes executi on. Kuna Szörtzile pol nud kaebajaid, siis antakse temale vitsu ja saadetakse maalt välja. ${ }^{1}$ 


\section{Villem Uuspuu}

II

1640. a. 28. augustil on Pärnu Maakohtu väljasõidu-istung Karksis. Arutusele tuleb härra J ohan Krausz'i kaebus oma talupoja Pavel Willapulck'ile, keda süüdistab nõiduses; ta meel itanud alamaid ja tekitanud kahju.

Küsitakse kaebealuselt, kas ta kaebaja juuresol ekul teinud terveks kaks härga, kui need olnud peaaegu surnud, tõmmates neid sarvist ja käega silitades üle nende selja?

Kas ta pealeseda veel kolm härga terveks tegi ja ütles, et härra, sinu härg peab jääma, teised aga surema? Kaebeal une võtab selle omaks ja ütleb, et kui kurat kedagi haigeks teeb, siis võib ta ka jälle ai data. Kui küsitakse, mil viisil kaebealune selliseid haigusi parandab, vastab ta, et võtab sool a ja lausub sellele: J umal, I sa ja Poeg, päästa mu loomad kõigest piinast, vaevast ja haigusest, kuna Sa loomad oled loonud meile kasuks. ${ }^{2}$ Neid sõnu ütleb ta kolm korda ja silitab käega loomi. Siis tervenevad loomad. Neid sõnu tarvitab ta ka Isa, Poja ja Püha Vaimu nimel ja kaheteistkümne apostli nimel inimeste arstimiseks, sääljuures lööb ta risti kolm korda väikese sõrmega, sülgab siis kolm korda soolale, mille haige peab siis vette panema. Siis tuleb vett kolm korda üle pea tõsta ja ära juua. Sõnad õppinud ta kellegilt vanalt mehelt, nimega Zösche, kes temale vastu tulnud metsa vahel Anne kiriku juures. Zöschel ol nud ka kurat kaasas, keda ta näinud puu otsas istumas, laps süles. Kurat ol nud "saksa moodi" siniseis rõivais. Küsitakse, kas ta on sageli näinud kuradit? Kaebeal une vastab, et esimene kord näinud kuradit Anne kiriku juures, teine kord oma hernepõllul, kolmas kord metsas marjul käies, neljas kord rabas, viies kord jälle metsas ja kuues kord oma talus. Viimane kord käskinud kurat temal endaga kaasa tulla ja lubanud näidata, kui palju inimesi ta maailmast saanud. Tema pole aga läinud. Kurat öel nud, et küll sa mulle veel järgned. Seitsmendal korral näinud ta jälle kuradit talus, kaheksandal korral mäel ja üheksandal korral tulnud ta tallu ja võtnud temalt vasika. Kümnendal korral näinud ta, kuidas kurat võtnud ema sülest tema lapse, kes alles oli ristimata ja poolteist nädal at vana. Laps surnud sellejärele. Kaebeal une ütleb, et ta kuradiga lepingus pole. Paluda ta aga ei oska. Kuradiga on ta ühenduses ajast, kui see ilmus temale kiriku juures. Küsimusele, kas ta kurja on teinud, vastab kaebealune, et andnud kuradile oma kaks 
kolme nädala vanust poega, kelle eest ta saanud 20 taalrit. Kui ta selle raha kätte võtnud, muutunud see aga söeks. Ka andnud ta kuradile oma kolm hobust, kuna võõraid pole saanud. See sündinud jaaniööl mäel, kus teda hästi vastu võetud söögi ja joogiga. Ütleb, et ta tunneb ka teisi nõidu. Kiewase Hen olevat nõid, kes palju paha teeb. Ta nõi dunud sõnadega Tyro J anuse lapse ja andnud kuradile. Ka nõidunud ta Kieke Hennu lapse ja teinud jälle terveks. Samuti nõidunud ta von Schlippenbachi veised, terveküla veised ja Kiekse Hanszu naise, et see jala murraks. Ta tahtnud ka von Schlippenbachilt elu võtta, pole aga saanud. Kiewase Henn ${ }^{3}$ öel nud seda ise temal e. Edasi tunnistab kaebealune, et Kiwy Hansz ja Norrekatz Matz oskavat ka lausuda ja soola puhuda.

Kaebealuselt küsitakse, mis ta "meistri" nimi ja kuidas ta välja näeb? Ütleb, et kuradil on jalad nagu kukel ja suured silmad. Tema nimi olla "Heiliger Pater". Lõpuks lubab oma sõnadest ja soolapuhumisest loobuda ja J umala poole pöörduda.

Otsus: Kuna kaebeal une vabatahtlikult end tunnistab süüdi nõidumises, kuradiga ühenduses olemises, lastele ja loomadele kahju tegemises, siis mõistetakse ta surma tulega põl etamise läbi. Otsus saadetakse õuekohtule kinnitamiseks. ${ }^{4}$

\section{III}

1640. a. 29. augustil on Pärnu Maakohtu väljasõidu-istung Karksis. Willapulck Pavel'i tunnistusealusel tuuaksekohtusseKiewase Hen, keda süüdistatakse kogu küla ja von Schlippenbachi veiste surnuks nõidumises.

Kuna kaebealune salgab, ähvardatakse teda veeprooviga (mit der Wasserprob gedreucket), mis aga ei anna tulemusi. Sellepääle kuulatakse üle uuesti Willapulck Pavel, kes jääb oma süüdistuse juurde.

Vahid, kes Kiewase Hen'u vangistanud ja siia toonud, ütl evad, et kaebealune võtnud teel taskust kivi ja selle alla neelanud. Hen ütleb, et see ol nud leib. Timukas otsib ta taskud läbi ja leiab sealt ühe kivi ja raha. Kaebealune ütleb, et tarvitab neid tule löömiseks.

Võetakse ette veeproov (auffs Wasser werffen Iassen), mille juures kaebealune jääb veele ujuma. Kuna ta aga ka selle järele salgab, seatakseta "silm silma vastu" Willapulck Paveliga, kes süüdis- 


\section{Villem Uuspuul}

tust kordab. Lisab veel juurde, et kaebealune Tyro Hanszo lapse ristsetel nõidunud Hilper J ack'u, nii et see verd süljanud. Hiljem teinud ta tema jälle terveks. Ka olla ta jaaniööl ol nud sinisel mäel (blauen Berge). Ta soovitab kaebealusel kõik üles tunnistada ja end mitte pi inata lasta. Kaebeal une vai dl eb enne vastu, tunnistab aga siis, et kurat õpetanud temale sõnad: Ponnase ki ewy nel ly teearro. ${ }^{5}$ Nende sõnade mõju katsetanud ta esite oma loomade juures, millest temal surnud kaks looma. Siis nõidunud ka von Schlippenbachi loomad. Küsitakse, kus kurat teda õpetas ja kui tihti temaga koos viibinud? Ütleb, et metsas, teinekord näinud kuradit ka järvel paadiga sõites. Kas ta või b terveks teha von Schlippenbachi haiged loomad? Kui lahti saab, lubab samade sõnadega terveks teha. Tunnistab ka viimaks, et nõidunud surnuks Kieckse Hennu lapse. Andnud ka kuradile oma ristimata kaheaastase tütre. Ka nõidunud ta Nossy Hennu kaks last. Nossy Henn andnud ise oma kolmeaastase ristimata tütre kuradile, sel le sinisele mäele viies. Kaebealune käinud igal jaaniööl sinisel mäel, kus kurat teda hästi vastu võtnud. Sääl ol nud palju süüa ja juua ja üldse väga lõbus. Willapulck Pavel ol nud sääl "isanda"köögimeister (Küchenmeister). Ta viinud jaaniööl Püha J acobile vasika, mille ta Schlippenbachilt võtnud. Selle eest tänatud teda ja kästud teinekord veel tuua. Kirikusse ei võivat ta aga minna, ei saavat siis enam "isandat" teenida. Ütleb, et N ossi Henn oskab sama, mis temagi. Ta varastanud von Schlippenbachi aidast vilja ja viinud selle koos nõiutud härjaga mäele. Nimelt olla nii, et neid mäele muidu vastu ei võeta, kui nad midagi kaasa ei too. Ka Putneck Lobbina ja Leppit Mart olla nõiad.

Otsus: Nõidumise ja kuradiga ühenduses ol emise eest mõistetakse kaebeal une surma tule läbi. Otsus saadetakse õuekohtule. ${ }^{6}$

\section{IV}

1640. a. 30. augustil jätkub Pärnu Maakohtu istung Karksis. Arutusel etuleb Wol mer von Schl i ppenbachi talupoja N ossy Hennu vastu tõstetud kaebus hukkamõistetud nõia Kiewase Hennu tunnistuse põhjal. Kaebealusele esitatakse Kiewase Hennu tunnistusi, mida see aga omaks ei võta. Si is ähvardatakse kaebealust veeprooviga. Kui aga ka ähvardus ei aita, visatakse kaebealune vette, millejuures ta jääb veele ujuma ka si is, kui teda latiga tõugatakse. Kui ka 
see ei mõju, seataksekaebeal une vastamisi Kiewase Hennuga, kes süüdistust kordab. Sellejäreleähvardatakse kaebealust piinamisega. Nüüd tunnistab ta, et oskab head teha sõnadega, milliseid õpetanud temale keegi vanamees. Sõnad on järgmised: Sina kuri vaim, tagane sellest Kristuse ini mesest (Du böser Geist, wei chewegk, von diesen Christus Menschen), sellejärele lausub ta sõnad: Lebey Ohö, Kiroh Kircko, Sura. Altare, Kusnett, Suret Meeset, peeatekse 7 Öeldakse kaebealusele, et need sõnad on kurjad ja tulevad kuradilt, kuna neid keegi ei mõista. Manitsetakse kaebealust tunnistada, mis ta nende sõnadega kurja on teinud.

Kaebeal une ütleb, et aidanud ai nult haigeid. Kuna Kiewase Henn jääb oma tunnistuse juurde ja kaebealune ei taha tunnistada, siis võetakse ette piinamine. Ühe korra pingutamise järele palub ta end lahti lasta ja lubab kõik tunnistada. Kui teda lahti lastakse, tunnistab et nõidunud Kiewase Hennu lapsed ja viinud kuradile, sellepärast et Henn temalt maa võtnud. Ka varastanud ta mõisahärralt ja mõnelt talupojalt vilja ja viinud selle koos härjaga, mida enne nõidunud, sinisel e mäele oma "isandale". Teab ka sõnu, millega kurja saab teha, mis kõlavad nii: tulle Minna Keick, tullo. mea I kkamisz woib, alle, Sullekeib. Minno pewia. ${ }^{8} \mathrm{~K}$ ui sellejärele võtta kolm rukkipead ja nendel õied ära murda, siis pi isab sellest kurja tegemiseks.

Kui küsitakse, kuidas kaebealune pääsenud mõisahärra aita, vastab see, et kurat andnud talle selleks võtme, mille jälle sinisel mäel ära võtnud. Kas ta nüüd võib ka kurja teha? Vastab, ei, kuna ta seisab kohtu ees. Edasi jutustab kaebealune, et nigulapäeval olla kurat põrgust väljas. Esimene kord rääkinud kurat temaga Paistu surnuaial. Mida kurat seal temale ütles, ei tunnista, kuna ta niigi teenib ajaliku karistuse. Edasi jutustab kaebealune, et ta läinud koos Kiewase Hennuga mäele ja viinud kaasa vasika, et mitte saada "isanda" vihaaluseks. Ütleb, et olnud ka libahunt. Kui ta hundi naha ümber pannud, muutunud hundiks ja teinud palju kahju. Kurat kutsunud teda tihti mäele ja käskinud härra Schlippenbachile kahju teha, mida ta aga pole teinud.

Teatab kohtule teisi nõidu ja palub armu, lubades mitte enam nõiduda. Nüüd teinud ta seda teiste meelitusel.

Otsus: Kuradiga ühenduses olemise, nõiduse läbi kahju tekitamise, varguse ja varastatud asjade sinisel e mäel eviimise eest mõistetakse kaebealune tulesurma. ${ }^{9}$ 


\section{Villem Uuspuu}

\section{V}

1636. a. 27. septembril on Krahvliku Linnusekohtu istung Pärnus. Arutusele tuleb Fromhold Leps'i kirjalik kaebus Andrese naise Rohttzi Beahtt'i vastu, milles süüdistab kaebealust oma naise haigeks nõidumises.

Kaebaja teatab kirjas järgmist: Minu ja minu laste äraol ekul tuli kaebealune pühapäeva hommi kul mõisa ja tahtis ilma küsimata minna mõisaproua juurde. Kui toatüdruk temalt põhjusi küsinud, öelnud ta, et viib prouale maasikaid. Kui aga proua toodud maasikaid sõi, jäi ta haigeks, kannatas aastaid mürgitust ja suri. Kui levis kuulujutt, et kaebealune on selles süüdi, vangistati ta. Süütuse tõendamiseks pidi ta kolm korda ümber surnu käima, oma käe surnu kohale panema ja ütlema: kui ma olen surmas süüdi, andku J umal mingi märk. Kaebealune ei tahtnud seda teha, vaid ütles, et proua temale andestab. Siis tuli ka Rohtzi Andres üksi ja ütles, et J umal andestab mõlemale naisele. Kui Andrest nõidumises süüdistati, ütles see, et võib mõnda tervendada ja hädast aidata. Palun kohut mõlemaid karistada, kuna tal upojad austavad mõlemaid kui ebajumalaid (Abgott), kes oma kunsti ja õnnistuse läbi teisi palju aitavad. Minu majale toovad nad aga palju kurja; ühel päeval suri hobune, teisel päeval kolm paari härgi, ka nägid minu teenijad naise eluruumis tonti, kes sealt läks talli. Palun süüdl asi mittekaristamata jätta.

Kaebealune eitab süüd. K ohus palub kaebajal oma süüdistust tõendada, milleks viimane saadab kohtusse tunnistajateks Abrahami naise Anna Bockmeieri ja oma toatüdruku EIse, Läärsi tütre.

Esimene neist tunnistab, et kaebealune toonud hommiku vara marju ja käskinud need prouale anda. Teine tunnistaja ütleb umbes sama. Lossiproua võtnud marjad vastu ja söönud, ülejäänud andnud temale. Naisele antud süüa ja juua. Ennem pole ta aga kunagi marju mõisa toonud. Proual paistetanud Iõuad, si is kael ja mõni päev enne surma ol nud üleni paistes. Pealesurma muutunud ta pruuniks ja ajanud verd välja. Vahepeal lisandub tunnistajaid. Härra Matthiasz Stahl kirjel dab, kuidas nad kaebeal use vi inud kirikusse ja lahtise kirstu ümber talutades käskinud öelda, kui olen süüdi, anna märki enesest. Kaebealune aga seda ei teinud, vaid öelnud, et proua andestab surma süü, mida ka teised juuresolijad kuulnud. Rohttzi Andres öel nud rootsi keeles, J umal andesta mõlemale naisele. $\mathrm{Ka}$ öelnud ta tunnistajaile, miks nad proua eluajal 
sellest ei rääkinud, tema oleks sellele veel abi saanud. Siis nimetanud teised ka teda nõiaks. Tema aga öel nud, et ta pole nõid, vaid tervendab "Meie I saga” inimesi. Küsitl etakse kaebealust. See räägib, et olla marju viinud, kuna sulane selleks õhtu andnud käsu. Laiba juures teinud ta kõik, mida teised nõudnud. Andestust ta pol e aga laibalt palunud. Ütleb veel, et tuleb andestust paluda kõigilt inimesilt ja J umalalt. Ta käinud mehega ühes ja aidanud teda õnnistamisel. Selle järel küsitletakse kaebealuse meest. See tunnistab, et tervendanud Kortti Hansz'u J umala sõnaga ja apostleid paludes. Kohus küsib, kas kurat olnud sel ajal mõisas, kui ta Hanszu tervendas. Kaebealune ei tea sellest midagi. Tema olnud Kortti Hanszu juures, pal unud rootsi keeles kätt Hanszu pea peal hoi des. Hansz tervenenud sellest ja tema saanud selle eest ühe šillingi.

Korral datakse Andresega veeproov kahel korral, mis aga timuka oskamatuse tõttu ebaõnnestub.

Otsus: Kuna süü poletõestatud, vabastataksekaebealuneBeahtt, tema mees, kes aga tuntud lausuja, saab kolm paari vitsu ja aetakse krahvkonnast välja. ${ }^{10}$

\section{VI}

1637. a. 6. juunil on Krahvliku Linnusekohtu istung Pärnus. Kaebajatena esinevad kõrtsmik Petter Wincküla ja talupojad Tamme Laur, Päep Andresz ja veel teised. Kaebealust Rohttzi ${ }^{11} \mathrm{~J}$ ürgenit süüdistatakse nõidumises. Petter Winnküll kaebab, et kaebealune nõidunud tema poja haigeks. 14. päeva eest tulnud ta Rittmeister Paleni juurest, kust ta saanud kalu. Rohttzi J ürgen, kes kõrtsis viibinud, palunud $\mathrm{ka}$ endale kala praadimiseks, kuna ta selliseid kalu pole söönud. Kui kala praetud, annud ta kaebealusele poole kalast, see pomisenud kalale, võtnud tema ümbert kinni ja pakkunud ka temale kala. Kaebaja pole kala tahtnud ja lasknud kaebealusel üksi süüa. See langenud aga peale kala söömist maha ja läinud paiste. J oonud küll kaks toopi õlut, poolteist toopi äädikat ja kannutäi e vett, see pole aga ai danud. Si is roninud ta käpuli kotta, kuhu jäänud seni, kuni kaebaja väikene poeg talle juua andnud. Peale selle saanud kohe paremaks, kaebaja poeg aga jäänud sellest silmapilgust haigeks.

Kaebaja poeg Behrentt ütleb, et kui tema kaebealusele juua andnud, jäänud ta haigeks ja paistetanud. Poisi ema tõendab sama. 


\section{Villem Uuspuu}

Petter Wincküll kaebab, et kaebealune juba nelja aasta eest teda nõidunud. Ta olnud kaheksa päeva palavikus, millest Rohttzi J ürgen lubanud tema tervendada kahe kapa õlle eest. Ta andnud kaebeal usele 4 kappa õlut, mille see ära joonud. Tema saanud terveks, aga üks lehm jäänud tal hai geks. J ärgmisel hommikul andnud ta veel kaebeal usele õlut, soolatud kalu ja liha.

Tamme Laur kaebab, et kaebealune tema poja surnuks nõidunud. Ühe aasta eest tülitsenud tema poeg sulase Paweliga. Viimane ähvardanud tema poega. Varsti peale seda jäänudki poeg haigeks, paistetanud, süljanud verd ja surnud neljateistkümne päeva pärast. Hiljem saanud ta teada, et sulane Pawel maksnud Rohttzi J ürgenile tema poja nõidumise eest pool külimittu soola ja vaka otri. Seda tõendavad ka Päep Andresze sõnad. Ta lisab veel juurde, et korra, kui kaebealuse väimees kinni pandud, ja tema pole tahtnud vastutada, ähvardanud teda kaebealune ja kol me päeva järel e kiskunud hundid tema lehmad Iõhki. Kui ta nelja aasta eest süüdistas kaebealust oma poja kadumises, ähvardanud viimane teda, mille tagajärjel tal surnud härg. Kui ta noominud kaebealust laiskuse pärast, hakanud see jälle sajatama ja ütelnud, et kurat ratsutab sinu hobuse seljas, mille peale hobune läinud arust ära ja surnud.

Neljas kaebaja räägib, et J ebbeda Thomasel varastatud vilja. See lubanud ülejäänud vilja nõiale, kes varga nõiub. Kaebealune lubanud seda teha, aga mitte enne, kui noore orase ajal. Sel ajal surnudki kahjusaaja vend, keda kahtlustatud vilja varguses.

Lesknaine Marrit kaebab, et kaebealune tema poja surnuks nõidunud. Mineval aastal ähvardanud ta tema poega, mida ka teised kuulnud. Poja matusel süüdistanud ta ka nõida. See aga öelnud, et küll J umal teeb kõik hästi ja keelanud sellest edasi rääkida.

Peep ${ }^{12}$ Andresz süüdistab veel kaebealust õlle nõidumises ja naisele valude tekitamises selga.

Kuulatakse veel kaebealune üle ja vannutatakse kaebajad ja tunnistajad. Need jäävad oma sel etuste juurde. Kaebeal une ütl eb, et kui kõik tema peale kaebavad, siis sureb ta hääl meelel, ega tahagi enam kaua elada.

Otsus: Mõistetakse surma põl etami se läbi. Peal e otsuse teadasaamist teatab kaebealune kohtule rea isikuid, kes tegelevad "künstidega", lausuvad ja "jooksevad". ${ }^{13}$ 
Villem Uuspuu

\section{VII}

1642. a. 4. märtsil on Pärnu Maakohtu väljasõidu-istung Karksis. Arutusel etuleb Wallame Bartmes'i, Wallame Hans'u, Halliste Peter'i ja tema naise kaebus Lupas Lauri vastu. Kaebealust süüdistatakse Bartmesi ja Hansu venna J ürgen'i ja Halliste Peter'i kahe lapse surnuks-nõidumises.

Kaebealune on vahistatud koos naisega. Naine olla aga öösel surnuks kägistatud. Kaebealune ütleb, et tema pole nõid. Naise tapnud vanglas "kuri vaenlane", kes koera kujul (Hundesz gestalt) vangla tulnud ja öelnud naisele, et see temaga kaasa peab tulema, siis kägistanud naise.

Wallame vennad kaebavad, et kaebeal une nende venna J ürgeni surnuks-nõidunud. Kaebealusel, kes nende naaber, ol nud kaebajate juures kast, kuhu ta vilja kogunud. J ürgen saanud teada, et kaebealunenendelt varastanud pool teist vakka rukkeid ja võtnud selle siis tagasi. Ka ähvardanud J ürgen kaebealust kohtuga. J ärgmisel päeval jäänud ta aga haigeks, hammustanud oma keele katki ja polevat enam rääkida saanud.

Kaebealune eitab süüd ja ütleb, et J ürgeni nõidunud tema naine, sepa naine ja Hirmp H orig oma naisega. N eed aga olla põgenenud. Kui ta vangi võetud, tulnud sepa naise poeg Laus ja aidanud tema vangist välja, viies oma majja.

Sepa naine andnud temale tüki leiba ja vöö ja käskinud Saaremaale põgeneda. Laus öel nud ka, et ta peab põgenema, muidu võetakse ka tema ema kinni. Vanglast aidanud ta teda nii välja, et Iõhkunud kirvega müüri augu ja andnud ka temale kirve. Laus ütleb, et ta pole põgenemisel kaasa aidanud. Kaebealune isetulnud nende juurde, kus ema talle andnud viisud ja vöö, et ta saaks edasi jooksta. Pika puiklemise järele tunnistab viimati Lupas Laur, et tema nõidunud teistega koos J ürgeni. Nad teinud seda mingi valge rohuga (Kraut) ja sõnadega, mida sepa naine õpetanud. Ta ei taha neid sõnu öelda, kuna need on kurjad ja nendega teenitakse kuradit. Kaebeal une seatakse sepa naisega vastamisi, kusjuures ütleb, et naine temale nõidust õpetanud ja temaga koos nõidunud J ürgeni, Leibase Hen'u ja Halliste Petri kaks last. Ütleb, et sepa naine juba neljakümneaasta eest õppinud Saaremaal nõidumist ja teinud palju kurja. Ka olla ta tihti koos kuradiga.

Sepa naine Marrit ei võta süüdistust omaks ja ütleb, et kui ta nõid on, oleks ta rikkam. Kaebealune aga täiendab oma seletusi 


\section{Villem Uuspuu}

Marriti suhtes ja ütleb, et ta tahtnud nõiduda koos tema naisega mõisahärra perenaise. Nad läinud ka selleks koos mõisa. Et perenaine aga palju palunud, pole nad muud saanud, kui et perenaine on tänapäevani haiglane. Nad teinud seda Puicken'i abil, kes olla enne lehmapiima imenud. Nad puistanud soola looma- ja hobusetalli ja kutsunud kuradi appi, sealjuures mõisaproua nimenimetades. Sõnad, mi da nad öel nud, on: Kol m. Kurratte, Tulla, Sola Peel. ${ }^{14}$ Kui neid sõnu öelda, tulla kolm kassi või kolm koera. Kui sõnad öeldud ja sool puhutud, tuleb kurat ja aitab.

Marrit eitab kõik öeldu, olla ai nult soovitanud kaebealusel Saaremaale põgeneda. Marritit vangla viies leitakse sealt kott, milles kuivatatud nahkhiir, vaha, soola ja villast lõnga. Kui Laurilt küsitakse, milleks ta neid asju tarvitanud, ei taha ta esiti tunnistada. Viimaks aga ütleb, et ta neid kasutab nõidumiseks. Soola tahtnud ta puistata kohtunikejalule. Lõnga ta seob endale paremale paljale käevarrele, kui tahab kurja teha. I ga kord aga lüheneb Iõng natukene.

Otsus: Lauri vabatahtliku ilma piinamiseta tunnistusejäreleselgub, et ta end andnud kurjale vaenlasele, J umalast lahkunud ja palju kurja teinud. Sellepärast mõistetakse kaebealune surma põletamise läbi. Sepa naise Marriti asjus otsustab kohus eel mise kaebealusetunnistuse põhjal, teda kui inimeste surnuks-nõidujat, esiteks piinata (ad torturam) ja ülestunnistamise järele põletada. Esial gu saavad mõlemad "sada vitsa" ja jäävad vangi. Vahepeal kästakse üles otsida Hirmo Horig ja tema naine. ${ }^{15}$

E smatrükk: Uuspuu, Villem 1937. Nõiaprotsesse Pärnu Maakohtu Arhiivist kuni 1642. Usuteadusl ineAjakiri 3/4, Ik 115-116.

\section{Kommentaarid ja kirjandus}

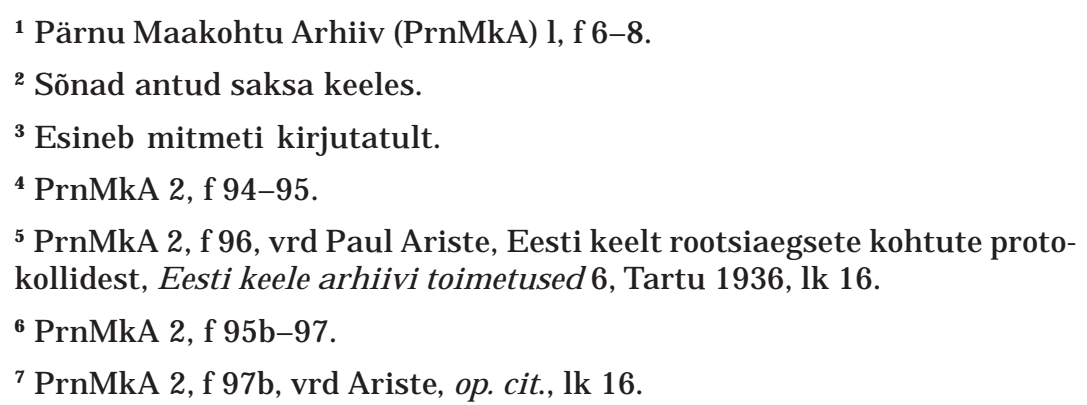




\section{VillemUuspuu}

${ }^{8}$ PrnMkA 2, f 98, vrd. Ariste op. cit., Ik 17.

9 PrnMkA 2, f 97-98.

10 PrnMkA I, f 30-35.

${ }^{11}$ Esineb mitmeti kirjutatult.

${ }^{12}$ Esineb ka Päep.

13 PrnMkA I, f 38-44.

${ }^{14}$ Ariste, op. cit. Ik 18, vrd PrnMkA 2, f 142.

15 PrnMkA 2, f 140-143. 